University of Nebraska - Lincoln

DigitalCommons@University of Nebraska - Lincoln

Distribution of three psocid species (Psocoptera: Liposcelididae) in different moisture gradients in wheat

John Diaz-Montano

USDA-ARS, john.diaz-montano@ars.usda.gov

James F. Campbell

USDA-ARS, james.campbell@usda.gov

Paul W. Flinn

USDA-ARS

James E. Throne

USDA-ARS, Manhattan, KS, james.throne@ars.usda.gov

Follow this and additional works at: https://digitalcommons.unl.edu/usdaarsfacpub

Diaz-Montano, John; Campbell, James F.; Flinn, Paul W.; and Throne, James E., "Distribution of three psocid species (Psocoptera: Liposcelididae) in different moisture gradients in wheat" (2014). Publications from USDA-ARS / UNL Faculty. 2058.

https://digitalcommons.unl.edu/usdaarsfacpub/2058

This Article is brought to you for free and open access by the U.S. Department of Agriculture: Agricultural Research Service, Lincoln, Nebraska at DigitalCommons@University of Nebraska - Lincoln. It has been accepted for inclusion in Publications from USDA-ARS / UNL Faculty by an authorized administrator of DigitalCommons@University of Nebraska - Lincoln. 


\title{
Distribution of three psocid species (Psocoptera: Liposcelididae) in different moisture gradients in wheat
}

\author{
John Diaz-Montano*, James F. Campbell, Paul W. Flinn, James E. Throne ${ }^{1}$ \\ Stored Product Insect Research Unit, USDA, Agricultural Research Service, Center for Grain and Animal Health Research, 1515 College Avenue, Manhattan, KS
} 66502, USA

\section{A R T I C L E I N F O}

Article history:

Accepted 29 July 2014

Available online 20 August 2014

\section{Keywords:}

Stored products

Liposcelis bostrychophila

Liposcelis entomophila

Liposcelis brunnea

Moisture preferences

\begin{abstract}
A B S T R A C T
Psocids can cause considerable economic losses to stored products by direct feeding, and they have become global pests during the last two decades. We studied the distribution of Liposcelis bostrychophila Badonnel (Psocoptera: Liposcelididae), Liposcelis entomophila (Enderlein), and Liposcelis brunnea Motschulsky in different moisture gradients (11-12-13\%, 11-13-15\%, and 13-14-15\%) and a control (13-13-13\%) in wheat using a circular metal arena, which has a removable metal divider that partitioned it into three rings (outer, middle and inner). Lipsocelis bostrychophila and L. entomophila preferred grain with the highest moisture content in the different gradients evaluated. In general, populations of Liposcelis brunnea equally preferred grain with moisture contents greater than or equal to $13 \%$. These results showed the moisture contents preferred for three of the main psocid pests of stored grains, and this could help in making better pest management decisions.
\end{abstract}

Published by Elsevier Ltd.

\section{Introduction}

Several psocids species emerged as important pests of stored products in the 1990s worldwide (Leong and Ho, 1994; Rees, 1994; Turner, 1994; Mills et al., 1992) and in the 2000s in the U. S. (Phillips and Throne, 2010; Throne, 2010) causing significant damage to several stored food products (McFarlane, 1982; Rees and Walker, 1990; Turner, 1994; Kučerová, 2002; Athanassiou et al., 2010b). Psocid control is difficult because management tactics, mainly insecticides, used for other stored-product pests are often not effective for control of psocids (Athanassiou et al., 2009). Several psocid species have shown resistance to phosphine (Ho and Winks, 1995; Nayak and Collins, 2008; Nayak et al., 1998, 2003), a broadly used fumigant in stored product facilities, and to different contact insecticides (Nayak et al., 1998, 2002, 2005; Dou et al., 2006; Guedes et al., 2008; Athanassiou et al., 2009, 2010a; Opit et al., 2012). Therefore, alternative methods to control and to monitor psocids are needed.

Although studies of the influence of environmental conditions such as temperature and moistures on growth and development of psocids have been conducted (Rees and Walker, 1990; Wang et al.,

\footnotetext{
* Corresponding author. Tel.: +1 (785) 776 2761; fax: +1 (785) 5375584.

E-mail address: john.diaz-montano@ars.usda.gov (J. Diaz-Montano).

1 Current address: USDA, Agricultural Research Service, San Joaquin Valley Agricultural Sciences Center, 9611 South Riverbend Avenue, Parlier, CA 93648, USA.
}

2000; Opit and Throne, 2009), much less is known about how these environmental conditions influence psocid behavior and distribution. Opit et al. (2009) studied the movement of psocids within steel bins ( $4.72 \mathrm{~m}$ diam. by $3.35 \mathrm{~m}$ high; 1200 bushels) of wheat and found that populations gradually increased from the summer, when wheat was placed in bins, through the fall and decreased during the winter. They also found that psocids were more abundant during the fall at the center of the bin where temperature and grain moisture content were higher that in other parts of the bin. Subsequently, Throne and Flinn (2013), using a 60-cm-diameter circular arena, studied the distribution of Liposcelis bostrychophila Badonnel (Psocoptera: Liposcelididae), Liposcelis entomophila (Enderlein), and Liposcelis paeta (Pearman) in three different temperature gradients $\left(20-24^{\circ} \mathrm{C}, 20-30{ }^{\circ} \mathrm{C}\right.$, and $\left.20-42{ }^{\circ} \mathrm{C}\right)$. They found that in general the three psocid species moved to the warmest region of the grain in the three gradients with the exception of the $20-42{ }^{\circ} \mathrm{C}$ temperature gradient where L. entomophila males preferred moderate temperatures and L. entomophila females were evenly distributed between the two warmest regions of the grain. These studies determined that psocids could move towards the warmer regions of the grain. Grain moisture levels are also likely to influence psocid movement patterns, but responses of psocids to moisture gradients or preference for specific moisture contents in the grain mass have not been studied. Understanding the ideal and detrimental temperature and humidity conditions for psocid development is critical to determine 
their ecological preferences, which can help in making pest management decisions. Therefore, the objective of this study was to determine the distribution of L. bostrychophila, L. entomophila, and Liposcelis brunnea Motschulsky in different moisture gradients.

\section{Materials and methods}

\subsection{Insect culture and materials}

The psocids used in this study, L. bostrychophila, L. entomophila, and L. brunnea (voucher specimens No. 202, 182, and 203, respectively, were deposited in the Kansas State University Museum of Entomological and Prairie Arthropod Research) are from colonies maintained at the U.S. Department of Agriculture, Center for Grain and Animal Health Research in Manhattan, KS. Cultures were reared on a diet of 95\% cracked hard red winter wheat (Titricum aestivum L. 'Santa Fe'), 2\% wheat germ (Natural Raw Wheat Germ, Bob's Red Mill Natural Foods Inc., Milwaukie, OR), 2\% brewer's yeast (MP Biomedicals, Solon, $\mathrm{OH}$ ), and $1 \%$ crisped rice cereal (Rice Krispies, Kellogg's Company, Battle Creek, MI) at $30{ }^{\circ} \mathrm{C}$ and $65 \% \mathrm{RH}$, with a photoperiod of 16:8 $\mathrm{h} \mathrm{L}: \mathrm{D}$.

\subsection{Moisture gradients}

The distribution of psocids in different moisture gradients was determined using a circular metal arena $(60 \mathrm{~cm}$ in diameter by $9 \mathrm{~cm}$ in height) (Flinn and Hagstrum, 1998, 2011). The arena was insulated with an attached base and a removable lid $(2 \mathrm{~cm}$ thick wood and $3.5 \mathrm{~cm}$ thick insulating foam on the outside) (Throne and Flinn, 2013). The arena had a removable metal divider that partitioned it into three rings (outer, middle, and inner). The outer, middle, and inner rings have eight, four, and one compartments, respectively, for a total of 13 compartments. Each outer compartment $(10.2 \mathrm{~cm}$ wide), each middle compartment (10.2 cm wide), and the inner compartment ( $7.6 \mathrm{~cm}$ wide) held between $1.3-1.5,1.5-1.7$, and $1.8-2.2 \mathrm{~kg}$ of wheat, respectively. The arena holds a total of $18.2-21 \mathrm{~kg}$ of wheat.

The moisture content at which wheat is usually stored is $13 \%$. Therefore, we tested three different moisture gradients (11-12-13\%, 11-13-15\% and 13-14-15\%) for L. bostrychophila females, and for females and males of $L$. entomophila and L. brunnea; and a control (13-13-13\%) for females and males of $L$. brunnea. The control data for $L$. bostrychophila females, and for females and males of $L$. entomophila was taken from a previous study (Throne and Flinn, 2013) that was conducted with the same environmental conditions used in this study. The moisture content of wheat was measured using a grain moisture tester (GAC2000, DICKEY-john Co., Auburn, IL). Water was added to the wheat to obtain the desired moisture content percentage (using a moisture conversion table for wheat). The wheat was shaken periodically during $24 \mathrm{~h}$, and then it was frozen to kill insects that might be present in the wheat and could interfere with the experiments. After $2 \mathrm{~d}$, the wheat was allowed to reach room temperature for ca. $6 \mathrm{~h}$, and then moisture content was measured again and slight adjustments were made if necessary. Twenty-four hours before the initiation of each experiment, the wheat was placed in closed plastic gallon jars (one per each compartment in the arena) in the same environmental chamber $\left(30{ }^{\circ} \mathrm{C}\right.$ and $\left.65 \% \mathrm{RH}\right)$ where the experiments were performed.

The wheat with the lowest moisture content of each gradient was placed in the outer ring, and the wheat with the highest moisture was placed in the inner ring. We did a test to observe if the response varied if the wheat with lowest and highest moisture was placed in the inner and outer ring, respectively, and the response was similar (data not shown). The compartments in the arena were filled with hard red winter wheat 'Santa Fe' with different moisture contents in each ring. Then, the metal divider was carefully removed so that the impressions of the compartments were visible on the surface of the wheat in order to release the insects. Ten, 12, and 15 psocids were released in each outer, middle, and inner compartment, respectively, for a total of 143 psocids. There were ca. seven psocids per $\mathrm{kg}$ of wheat. The arena was covered with the lid and left in the dark in an environmental chamber $\left(30{ }^{\circ} \mathrm{C}\right.$ and $65 \%$ $\mathrm{RH})$. After $24 \mathrm{~h}$, the metal divider was reinserted into the wheat, the wheat from each compartment was vacuumed into gallon glass jars coated inside the upper rim with Polytetrafluoroethylene (60 wt. \% dispersion in water, Sigma-Aldrich Co., St. Louis, MO) to prevent psocid climbing and avoid escapes, the wheat was sieved using a U.S. standard \#10 sieve (2-mm hole size), and the material left (broken wheat kernels and dust) was sieved again using a U.S. standard \#30 sieve (0.6-mm hole size) to remove psocids. Then, the number of psocids in each compartment was counted. There were three replications of each of the three moisture gradients and the control for each psocid species evaluated except for L. bostrychophila (moisture content 11-13-15\%) and L. entomophila females (moisture content 11-12-13\%) with four replications each. At the end of the experiment, the moisture content of wheat was measured again. For each experiment, fresh wheat was used and subjected to the method described above.

\subsection{Statistical analyses}

The density of psocids was calculated in each of the three rings (inner, middle, outer) at the end of each replication by dividing the number of psocids in each ring by the weight of the wheat in each ring (density = number of psocids/kg of wheat). Then, we added the densities of psocids in the three rings in a replication to give the total density in the arena, and divided the density in each of the three rings by the total density for the arena. The proportion of the total density that was in each ring at the end of each replication was calculated, and these data were used to test whether the final distribution of psocids in the arena varied among the three rings. The data is presented as percentages (i.e., proportion*100). The data were analyzed using the General Linear Models procedure, and multiple comparisons were conducted using Ryan-Einot-Gabriel-Welsch Multiple Range Test (SAS Institute, 2008).

\section{Results}

Liposcelis bostrychophila. A significantly greater percentage of females was recovered in the ring with the highest moisture content (M.C.) in all three moisture gradients: first gradient $(11-12-13 \%)(F=77.3 ; \mathrm{df}=2,6 ; P<0.001)$ (Fig. $1 \mathrm{~A})$; second gradient $(11-13-15 \%)(F=54.3 ; \mathrm{df}=2,9 ; P<0.001)$ (Fig. 1B); and third gradient $(13-14-15 \%)(F=141.4 ; \mathrm{df}=2,6 ; P<0.001)$ (Fig. 1C). In the first and second moisture gradients where there was a ring with $11 \%$ M.C. wheat, this ring had a significantly lower percentage of the psocids. In the third moisture gradient, there was no difference in the percentage of psocids present in 13 and 14\% M.C. wheat. In the control treatment (13-13-13\%), a significantly $(F=9.2$; $\mathrm{df}=2,6 ; P=0.015$ ) greater percentage of psocids was found in the outer and inner rings compared with the middle ring (Fig. 1D).

Liposcelis entomophila. A significantly greater percentage of females was found in the wheat in the ring with the highest moisture content in the first moisture gradient $(11-12-13 \%)(F=16.5 ; \mathrm{df}=2$, 9; $P<0.001$ ) (Fig. 2A), in the second moisture gradient $(11-13-15 \%)(F=117.6 ; \mathrm{df}=2,6 ; P<0.001)$ (Fig. $2 \mathrm{~B})$, and in the third moisture gradient $(13-14-15 \%)(F=268.0$; df $=2,6$; $P<0.001$ ) (Fig. 2C). The rest of the psocids were distributed evenly 

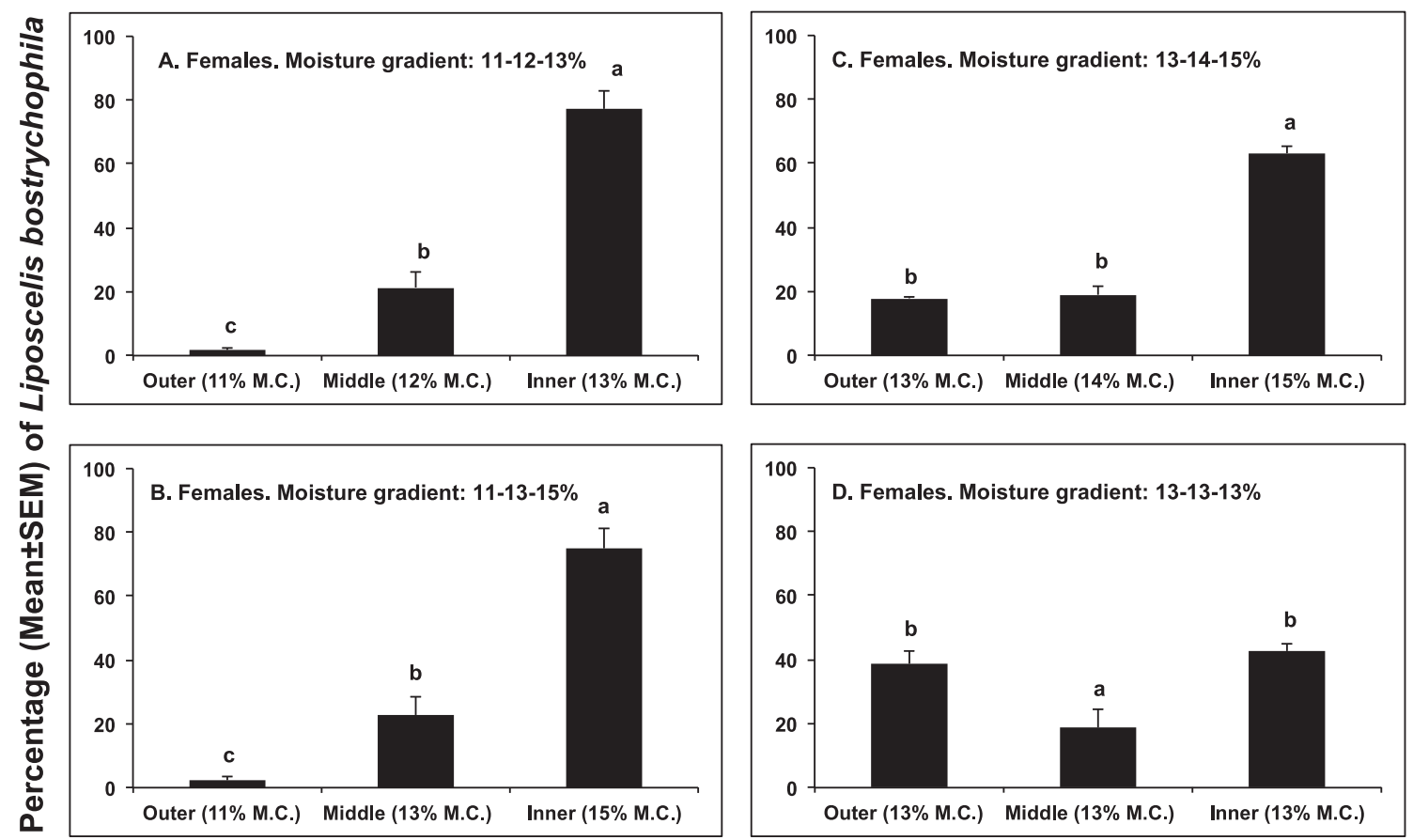

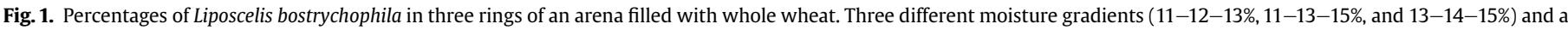

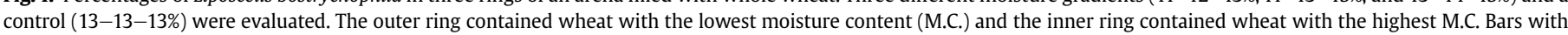
different letters are significantly different $(P<0.05$; Ryan-Einot-Gabriel-Welsch Multiple Range Test).

in the first and second moisture gradients in the other two rings (11-12\%) and (11-13\%), respectively. In the third moisture gradient, a statistically greater percentage of psocids were found in the middle ring (14\% M.C.) than in the outer ring (13\% M.C.). Psocids were equally distributed in the control treatment (13-13-13\%) $(F=2.9 ; \mathrm{df}=2,6 ; P=0.133$ ) (Fig. 2D).

Similarly to $L$. entomophila females, a significantly greater percentage of male psocids was found in the ring with the highest moisture content in all three moisture gradients: first moisture gradient $(11-12-13 \%)(F=162.2 ; \mathrm{df}=2,6 ; P<0.001)$ (Fig. $2 \mathrm{E})$, second moisture gradient (11-13-15\%) $(F=706.8$; $\mathrm{df}=2,6$; $P<0.001$ ) (Fig. 2F), and in the third moisture gradient (13-14-15\%) $(F=37.5 ; \mathrm{df}=2,6 ; P<0.001)$ (Fig. $2 \mathrm{G})$. The rest of the psocids were distributed evenly in the first and third moisture gradients. In the second moisture gradient, a statistically greater percentage of psocids was found in the middle ring (13\% M.C.). In the control treatment $(13-13-13 \%)$, a significantly $(F=19.6 ; \mathrm{df}=2,12 ; P<0.001)$ greater percentage of psocids was found in the outer ring (Fig. $2 \mathrm{H}$ ).

Liposcelis brunnea. There was a tendency to have a significantly greater percentage of females in rings with greater than or equal to $13 \%$ M.C., but to not exhibit differences in percentage of psocids among moisture contents of $13 \%$ or greater. In the first moisture gradient (11-12-13\%), a greater percentage of psocids was recovered in the ring with the highest moisture content (13\% M.C.), and a greater percentage of psocids was found in the $12 \%$ M.C. middle ring than in the $11 \%$ M.C. outer ring $(F=114.9 ; \mathrm{df}=2,6 ; P<0.001)$ (Fig. 3A). In the second moisture gradient (11-13-15\%), psocids were found equally in the two highest moisture content rings: the $15 \%$ M.C. inner and 13\% M.C. middle rings $(F=44.6$; $\mathrm{df}=2,6$; $P<0.001$ ) (Fig. 3B). In the third moisture gradient (13-14-15\%), there were no significant $(F=0.03 ; \mathrm{df}=2,6 ; P=0.970)$ differences in the distribution of psocids across the rings (Fig. 3C).

Liposcelis brunnea males showed a similar pattern to the females, except in the second moisture gradient (11-13-15\%), where a greater percentage was recovered at the intermediate 13\% M.C. In the first moisture gradient $(11-12-13 \%)$, a significantly greater percentage of psocids $(F=172.9 ; \mathrm{df}=2,6 ; P<0.001$ ) was found in the wheat with the highest M.C. (13\%). A statistically greater percentage of psocids was found in the middle ring (12\% M.C.) than in the outer ring (11\% M.C.) (Fig. 3E). In the second moisture gradient (11-13-15\%), a significantly greater percentage of psocids $(F=17.3$; $\mathrm{df}=2,6 ; P<0.001)$ was found in the wheat in the middle ring $(13 \%$ M.C.). The rest of the psocids were distributed evenly in the outer (11\% M.C.) and inner (15\% M.C.) rings (Fig. 3F). In the third moisture gradient (13-14-15\%), psocids were distributed equally $(F=1.4$; $\mathrm{df}=2,6 ; P=0.329$ ) (Fig. 3G). Female $(F=2.9 ; \mathrm{df}=2,6 ; P=0.134)$ (Fig. 3D) and male $(F=1.4 ; \mathrm{df}=2,6 ; P=0.320$ ) (Fig. $3 \mathrm{H}$ ) psocids were equally distributed in the control treatment (13-13-13\%).

\section{Discussion}

Overall, the three psocid species evaluated showed a tendency to accumulate in the grain with the highest moisture content, but L. brunnea did not appear to discriminate among moisture contents greater than or equal to $13 \%$. L. brunnea showed different behaviors between males and females in the 11-13-15\% moisture gradient, with females equally recovered in the two highest moisture contents but more males recovered from the $13 \%$ intermediate moisture content. Rees and Walker (1990) determined that L. bostrychophila and L. entomophila population growth was highest at $70-80 \% \mathrm{RH}$, and these species did not survive below $60 \% \mathrm{RH}$, while $L$. brunnea population growth was highest between 55 and 63\% RH (Opit and Throne, 2009). This could explain our results where L. bostrychophila and $L$. entomophila always preferred the highest moisture contents of grain provided because they required higher relative humidity compared to L. brunnea populations, which had humidity requirements that are lower and they show no preference between grain of 13 or $15 \%$ moisture contents.

In the control treatment (moisture gradient 13-13-13\%), psocids in general were distributed equally in the three rings, but there 

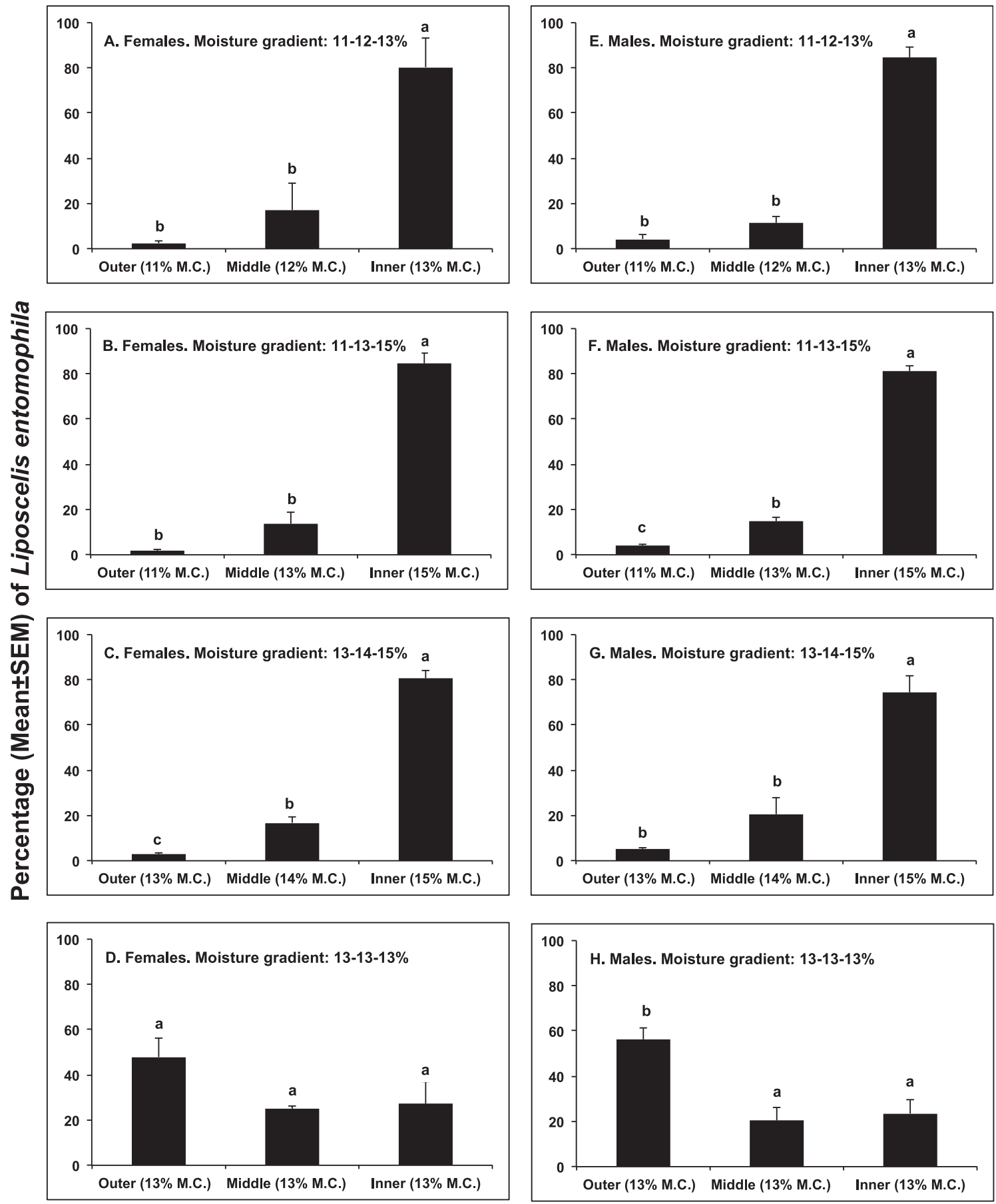

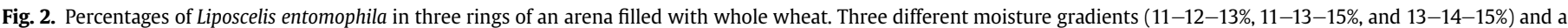

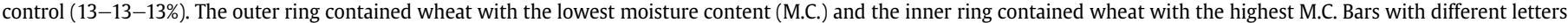
are significantly different $(P<0.05$; Ryan-Einot-Gabriel-Welsch Multiple Range Test).

were cases where some rings had significantly greater percentages of psocids. There was a significantly greater percentage of L. bostrychophila females found in the inner and outer rings (ca. 40\% in each ring) compared with $20 \%$ in the middle ring, and there was a significantly greater percentage of $L$. entomophila males present in the outer ring (56\%) than in the other two rings. The slightly greater percentages of $L$. bostrychophila and $L$. entomophila males in the outer ring could be explained by the highest number of psocids released at the beginning of the experiment in the outer ring (80) compared with the numbers in the middle (48) and inner (15) rings, and perhaps many of the psocids did not move or their movement was minimal because the moisture content was the same $(13 \%)$ in all three rings.

The recovery rates of psocids in this study were lower compared to other studies that used the same system but with considerably bigger insects: the rusty grain beetle, Cryptolestes ferrugineus (Stephens) (Flinn and Hagstrum, 1998) and the lesser grain borer, Rhyzopertha dominica (F.) (Flinn and Hagstrum, 2011). The recovery rates were between $75-94 \%$ for L. bostrychophila, $69-94 \%$ for L. entomophila females, $41-73 \%$ for $L$. entomophila males, $65-85 \%$ 

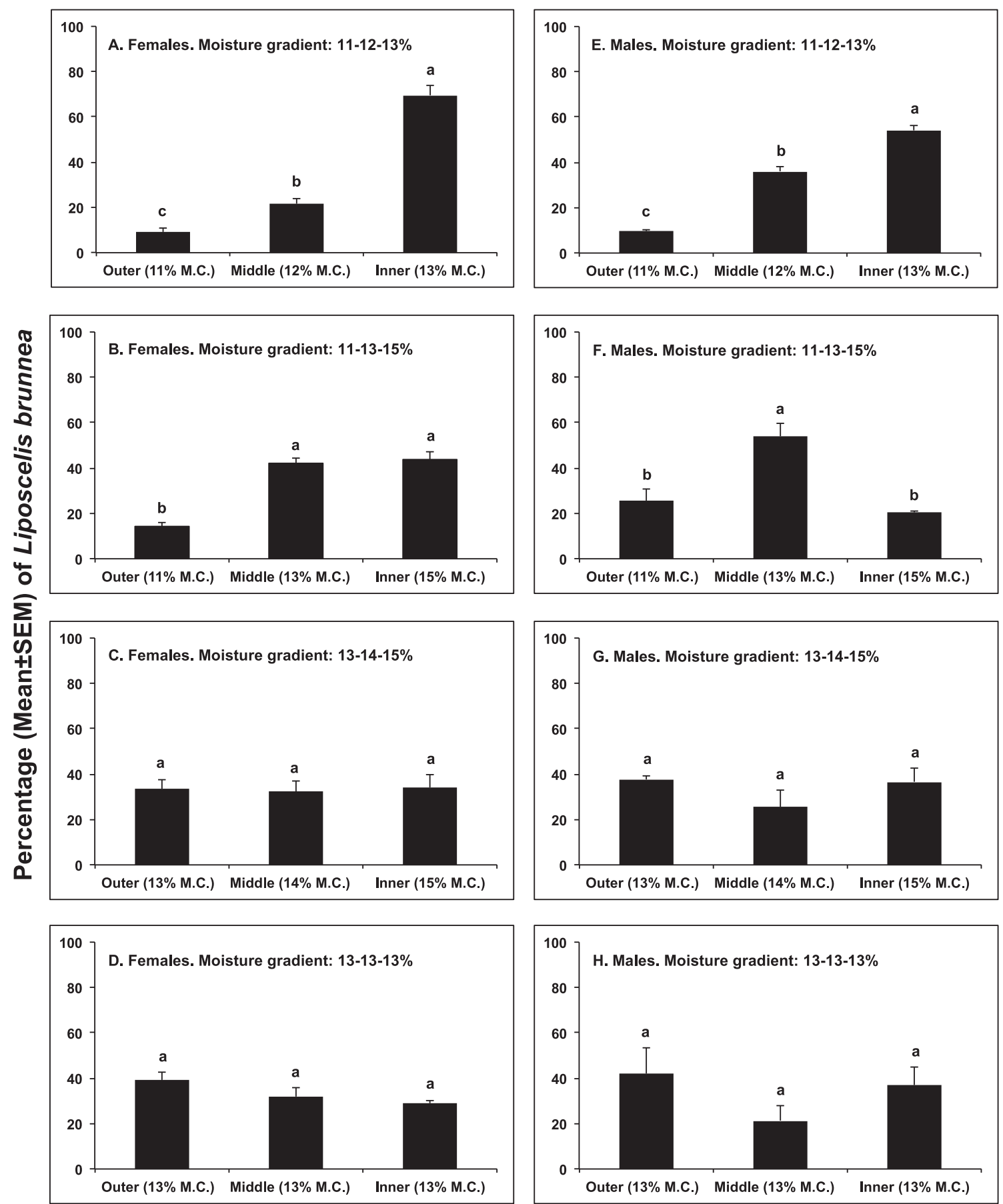

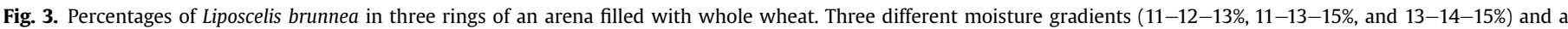

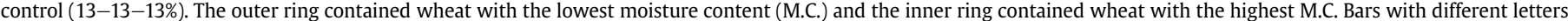
are significantly different $(P<0.05$; Ryan-Einot-Gabriel-Welsch Multiple Range Test).

for $L$. brunnea females, and $65-80 \%$ for $L$. brunnea males. There are several possible reasons for this outcome, and all are a result of smaller insects being more difficult to recover from grain. First, males are smaller than females. Second, L. bostrychophila are larger than the other two-psocid species studied. And finally, psocids are very small (ca. $1 \mathrm{~mm}$ long), and it is not easy to recover such small insects in ca. $20 \mathrm{~kg}$ of wheat.

The temperatures and relative humidities required for development and reproduction of $L$. bostrychophila (Rees and Walker, 1990; Wang et al., 2000), L. entomophila (Rees and
Walker, 1990), L. brunnea (Opit and Throne, 2009) and other psocid species vary among species. Different temperatures and moisture contents in wheat create different relative humidities. This may impact their movement and preferred location in grain stored in bins (Opit et al., 2009) or in different temperature (Throne and Flinn, 2013) and moisture gradients as demonstrated in this study. This research shows how psocids respond to different moisture gradients in grain, which can help to improve sampling methods and to make better pest management decisions. 


\section{Acknowledgments}

We thank Ann Redmon and Ken Friesen for excellent technical assistance. Mention of trade names or commercial products in this publication is solely for the purpose of providing specific information and does not imply recommendation or endorsement by the U.S. Department of Agriculture. USDA is an equal opportunity provider and employer.

\section{References}

Athanassiou, C.G., Arthur, F.H., Throne, J.E., 2009. Efficacy of grain protectants against four psocid species on maize, rice and wheat. Pest Manag. Sci. 65, $1140-1146$

Athanassiou, C.G., Arthur, F.H., Throne, J.E., 2010a. Efficacy of methoprene for control of five species of psocids (Psocoptera) on wheat, rice, and maize. J. Food Prot. 73 , 2244-2249.

Athanassiou, C.G., Opit, G.P., Throne, J.E., 2010b. Influence of commodity type, percentage of cracked kernels, and wheat class on population growth of storedproduct psocids (Psocoptera: Liposcelidae). J. Econ. Entomol. 103, 985-990.

Dou, W., Wang, J.J., Zhao, Z.M., 2006. Toxicological and biochemical characterizations of GSTs in Liposcelis bostrychophila Badonnel (Psocop., Liposcelididae). J. Appl. Entomol. 130, 251-256.

Flinn, P.W., Hagstrum, D.W., 1998. Distribution of Cryptolestes ferrugineus (Coleoptera: Cucujidae) in response to temperature gradients in stored wheat. J. Stored Prod. Res. 34, 107-112.

Flinn, P.W., Hagstrum, D.W., 2011. Movement of Rhyzopertha dominica in response to temperature gradients in stored wheat. J. Stored Prod. Res. 47, 407-410.

Guedes, R.N.C., Campbell, J.F., Arthur, F.H., Opit, G.P., Zhu, K.Y., Throne, J.E., 2008 Acute lethal and behavioural sublethal responses of two stored-product psocids to surface insecticides. Pest Manag. Sci. 64, 1314-1322.

Ho, S.H., Winks, R.G., 1995. The response of Liposcelis bostrychophila Badonnel and L. entomophila (Enderlein) (Psocoptera) to phosphine. J. Stored Prod. Res. 31, 191-197.

Kučerová, Z., 2002. Weight losses of wheat grains caused by psocid infestation (Liposcelis bostrychophila: Liposcelididae: Psocoptera). Plant Prot. Sci. 38 103-107.

Leong, E.C.W., Ho, S.H., 1994. Relative tolerance of Liposcelis bostrychophila (Bad.) and L. entomophila (End.) to some organophosphorus and carbamate insecticides. Int. J. Tropical Insect Sci. 15, 343-349.

McFarlane, J.A., 1982. Damage to milled rice by psocids. Trop. Stored Prod. Inf. 44, 3-10.

Mills, J.T., Sinha, R.N., Demianyk, C.J., 1992. Feeding and multiplication of a psocid Liposcelis bostrychophila Badonnel (Psocoptera: Liposcelidae) on wheat, grain screenings, and fungi. J. Econ. Entomol 85, 1453-1462.

Nayak, M.K., Collins, P.J., 2008. Influence of concentration, temperature and humidity on the toxicity of phosphine to the strongly phosphine resistant psocid
Liposcelis bostrychophila Badonnel (Psocoptera: Liposcelididae). Pest Manag. Sci. 64, 971-976.

Nayak, M.K., Collins, P.J., Reid, S.R., 1998. Efficacy of grain protectants and phosphine against Liposcelis bostrychophila, L. entomophila, and L. paeta (Psocoptera: Liposcelididae). J. Econ. Entomol. 91, 1208-1212.

Nayak, M.K., Collins, P.J., Kopittke, R.A., 2002. Comparative residual toxicities of carbaryl, deltamethrin and permethrin as structural treatments against three liposcelidid psocid species (Psocoptera: Liposcelididae) infesting stored commodities. J. Stored Prod. Res. 38, 247-258.

Nayak, M.K., Collins, P.J., Pavic, H., Kopittke, R.A., 2003. Inhibition of egg development by phosphine in the cosmopolitan pest of stored products Liposcelis bostrychophila (Psocoptera: Liposcelididae). Pest Manag. Sci. 59, 1191-1196.

Nayak, M.K., Daglish, G.J., Byrne, V.S., 2005. Effectiveness of spinosad as a grain protectant against resistant beetle and psocid pests of stored grain in Australia. J. Stored Prod. Res. 41, 455-467.

Opit, G.P., Throne, J.E., 2009. Population growth and development of the psocid Liposcelis brunnea (Psocoptera: Liposcelididae) at constant temperatures and relative humidities. J. Econ. Entomol. 102, 1360-1368.

Opit, G.P., Throne, J.E., Flinn, P.W., 2009. Temporospatial distribution of the psocids Liposcelis entomophila and L. decolor (Psocoptera: Liposcelididae) in steel bins containing wheat. J. Econ. Entomol. 102, 1369-1376.

Opit, G.P., Arthur, F.H., Throne, J.E., Payton, M.E., 2012. Susceptibility of storedproduct psocids to aerosol insecticides. J. Insect Sci. 12, 1-14.

Phillips, T.W., Throne, J.E., 2010. Biorational approaches to managing stored-product insects. Annu. Rev. Entomol. 55, 375-397.

Rees, D. 1994. Distribution and status of psocoptera infesting stored products in Australia. In: Highley, E., Wright, E.J., Banks, H.J., Champ, B.R. (Eds), Proceedings of the 6th International Working Conference on Stored-product Protection, 17-23 April 1994, Canberra, Australia. CAB International, Wallingford, United Kingdom, pp. 583-587.

Rees, D.P., Walker, A.J., 1990. The effect of temperature and relative humidity on population growth of three Liposcelis species (Psocoptera: Liposcelidae) infesting stored products in tropical countries. Bull. Entomol. Res. 80, 353-358.

SAS Institute, 2008. SAS 9.2 for Windows. SAS Institute Inc., Cary, NC.

Throne, J.E., 2010. Overview of North American stored product research. In: Carvalho, M.O., Fields, P.G., Adler, C.S., Arthur, F.H., Athanassiou, C.G., Campbell, J.F., Fleurat-Lessard, F., Flinn, P.W., Hodges, R.J., Isikber, A.A., Navarro, S., Noyes, R.T., Riudavets, J., Sinha, K.K., Thorpe, G.R., Timlick, B.H., Trematerra, P., White, N.D.G. (Eds.), Proceedings of the 10th International Working Conference on Stored Product Protection, 27 June-2 July 2010, Estoril, Portugal. Julius Kühn-Institut, Berlin, Germany, pp. 42-49.

Throne, J.E., Flinn, P.W., 2013. Distribution of psocids (Psocoptera) in temperature gradients in stored wheat. J. Stored Prod. Res. 55, 27-31.

Turner, B.D., 1994. Liposcelis bostrychophila (Psocoptera: Liposcelidae), a stored food pest in the UK. Int. J. Pest Manag. 40, 179-190.

Wang, J.J., Tsai, J.H., Zhao, Z.M., Li, L.S., 2000. Development and reproduction of the psocid Liposcelis bostrychophila (Psocoptera: Liposcelididae) as a function of temperature. Ann. Entomol. Soc. Am. 93, 261-270. 